PJER, Vol 4, Issue 1 (2021)

Women leadership in...

\title{
WOMEN LEADERSHIP IN THE ACADEMIA: A VOICE OF UNIVERSITY TEACHERS
}

\author{
Sadia Shaukat \\ Associate professor, \\ Department of Education, University of Education, \\ Lahore, Pakistan \\ Email: sadia.shaukat@ue.edu.pk

\section{Kiran Shahzadi} \\ Lecturer, \\ Department of Education, University of Education, \\ Lahore, Pakistan \\ Email: kiran.shahzadi@ue.edu.pk

\section{Farzana Yousaf} \\ Lecturer, \\ Department of Education, University of Education, \\ Lahore, Pakistan \\ Email: farzana.yousaf@ue.edu.pk
}

\begin{abstract}
Considering the stereotypical views that affect women who aspire to high-ranking leadership roles in higher education, this study determines the perceptions of teachers about their role in the academic. This study was qualitative that invited women and men in higher education institutes to participate in the interviews to determine their understanding about the representation of women leadership roles in higher education. Followed by the open-ended interview questions about the evident factors that influence the workplace behavior, and barriers that represent the prejudice toward women as leaders. Analysis performed by NVIVO indicated that women leadership role in the academia is challenging as they avail less opportunities to demonstrate their role as administrator. Due to the stereotypical views of society regarding women empowerment and leadership role, women attitude towards their leading positions in career is relatively marginalized. The study revealed that stereotypical views of female behavior had little impact on the successful careers of the participants. The participants revealed little significance to experiences with social role expectations and characteristics of women leadership. The participants' perception of their success was due to merit; the recognition by others as having the qualities and skills to lead in a variety of positions.
\end{abstract}




\section{KEYWORDS}

Women Leadership; Academia; Stereotyped Attitude; University

\section{INTRODUCTION}

Women participation in leadership positions have been debated and discussed in all fields of life encompassing entrepreneurship, administration, health and education. Women have shown their worth as a leader by breaking the mythical perceptions kept about them to remain away from leadership regardless of the presence of required skills and abilities (Tutorialpoints, 2020).Women have contributed their role in the business sector through widening the scope of novelty in the market and creation of jobs that resulted in the economic development of a country (Bruin et al., 2006). It suggests that giving place to women in leadership roles would create variety of talents among leadears based on the inclusion of varied thinking patterns in the organizations. Thus, there is no point to underestimate the female contribution to the economy (Lechman and Okonowicz, 2013).

Evidently, a person irrespective of the gender is able to learn these traits and exhibit when required. Consequently, the remarks given above undervalue the notion that leadership is masculine (Eklund, Barry and Grunberg, 2017). It seems that women participation at leadership positions is a human right considering their ability to participate equally with their male counterparts in all aspects of life including household or the country at a large scale (Hoare and Gell, 2009). According to common wealth report, efforts are being made to increase the number of women in a variety of leadership roles through legislation, regulation and government policies (Morley \& Crossouard, 2015). Regardless of the efforts made to upgrade the status of women at higher level, it is observed that women participation remained low even in the sector of education at higher level. According to scholars, womens are not more than one third represented as leaders in institutions of higher education (Cook, 2011; Gallant, 2014). This has led to an inference that there might be a hidden prejudice toward women seeking positions of leadership. Although, women are found to achieve milestones in social as well as workplaces since since 1960s, while comprising $45 \%$ of the workforce. Inspite of all this, their participation in leadership roles is not comparable to their male counterparts (Cook \& Glass, 2014; Eagly, 2007; Madden, 2011).

It is a well-accepted fact that we have qualified women enough to play leadership roles based on their participation in academic activities more often as compared to males. Universities find high enrollment rate of female in most of the faculties except for some professional degrees. Regardless of their participation in academic task, their lacking role in leadership positions shows some sort of inherent mechanism responsible for such phenomena (Maaitah et al., 2012). Women in Asian cultures 
occupying leadership roles as approximately half as compared to share by Europe, Australia and North America (Morley \& Crossouard, 2015). It is found that females are mostly found to lead a traditional career path toward top academic positions. They become well-known as faculty and scholars within higher education.

It is also observed that women exhibited characteristics leading to effective performance more often than men did; the stereotypical view of women in the workforce puts focus on feminine attributes or gender roles rather than leadership style (Braun, Peus, \& Frey, 2012). Exploring the reasons of missing role of women in the leading positions of academia through interview protocols will contribute into the body of literature review regarding the barriers and challenges that women face while pursuing their management positions. This research adds to the body of knowledge regarding perceptions of female behavior and its effect on women who aspire to highranking leadership roles in higher education.

\section{LITERATURE REVIEW}

Historically, leadership was considered as inherent, that led to the development of great man theory in 1869 by Galson (McCleskey, 2014). According to this theory, only men were happened to be the leaders. Considering its nature being intrinsic, the concept did not have any scientific base (Maloş, 2012). Consequently, following decades challenged the view of great man theory and was redefined (McCleskey, 2014).

Trait theory research on leadership identifies and measures individual personality characteristics found in great leaders (Maloş, 2012). In response to trait theories, behaviorists proposed behavioral theories from 1940 to 1950s focusing behavior of leaders not the characteristics (Bolden et al, 2003). As a result, observable actions of leaders were classified into clusters called styles of leadership. Therefore, it was concluded that leaders are made not born (Maloş, 2012). In the modern era, leadership theories have shifted from characteristics and behaviors to explicit actions of leaders shown and are categorized as transformational and transactional leadership. According to Bolden et al., (2003), situational theory and contingency theory emphasize the type of behavior the leader should display under any given situation (Keskes, 2014; Hechanova \& Cementina-Olpoc, 2013).

\section{Barriers to Female Leadership}

Women aspiring to have leadership roles face various challenges caused by stereotypical myths about gender and role expectations from a leader (Chin, 2011; Christman \& McClellan, 2012; Eagly \& Chin, 2010; Eagly \& Karau, 2002; Ely et al., 2011; Haveman \& Beresford, 2012; Rudman, Moss-Racusin, Phelan, \& Nauts, 2012). Scholars have used metaphors to represent these challenges such as the glass ceiling, the ivory basement, and velvet ghetto situations that impede women to achieve success 
in their careers (DeFrank-Cole et al., 2014). Glass ceiling effect can be explained as circuitous movement towards leadership or inability to cope with the challenges encountered following a career path (Eagly and Carli, 2009). Moreover, another form of gender bias include beliefs about gender, workplace structures, practices and patterns favoring male leaders and discourage female to opt for leadership or maintain their roles as leaders (Ely et al, 2011).

The journey of obstacles does not end here but its scope is wider as according to Ely et al., (2011) women face challenges including external environmental and contextual as well (De Frank-Cole et al., 2014; Ely et al., 2011) such as women leaders are perceived from typical leadership definitions based on masculine characteristics. Individuals develop a leader-identity by acting accordingly and from feedback that positively or negatively reinforce or negate their actions (Ely et al., 2011; Johnson et al., 2008; Madden, 2011).

Women are pressurized due to social obligations inside or outside of the workplace. One way of helping women leaders is to provide assistance in dealing such stereotypes about women as a leader (Ely et al., 2011). Feeling inability to manage home and work is another major cause behind women seeking leadership roles (Haile et al., 2016). The organizations failing to provide assistance to women to accommodate work home responsibilities create more chances for women to not pursue leadership roles. In conclusion, role congruity theory and societal roles become the major causes against women leadership roles.

Studies report that women aspire to have careers helpful in maintaining work home responsibilities such as teaching, nursing or social work (Parker, 2015; Finstad Million $\&$ Naschberger, 2014). Females were found able to reach top level positions through following the career development opportunities. It establishes the outcome that female are optimistic, committed and able to excel in leadership roles (Laud \& Johnsons', 2013). There is also a question of whether the choices women make are really choices. Haveman and Beresford (2012), argue that choices, such as education, field to study, working outside the home, full-time work or part-time are often constrained by culture the women comes from.

\section{Case of the Study}

The disparity between the high number of women who obtain a higher degree and the underrepresentation of women in the executive leadership roles is problematic. The discrepancy persists when women are welcome to receive a higher education yet they are not welcome to undertake leadership responsibilities in colleges and universities (Lennon et al., 2013). The article contributes to the existing literature addressing the stereotypical conceptions of people regarding women as leaders in general and 
education in specific. This paper derives from perceptions of teacher educators regarding role of women leaders in academia working in universities of Lahore. The study was based on open ended interview approach providing freedom of expression to respondents.

\section{RESEARCH OBJECTIVES}

1. To determine the perceptions of university faculty regarding women leadership role in the academia

2. To explore the challenges faced by women for pursuing leadership roles in the academia

\section{RESEARCH METHODOLOGY}

This particular study design was selected based on the conviction that it would help researchers to study individual experiences using the framework of constructivism. Following this approach, themes are generated based on the data collected asking individuals their personal experiences. The central question posed to answer as a result of this study was the underrepresentation of women leadership roles in higher education. The study was exploratory in its nature that would allow researchers to be able to convert meanings of individual experiences regarding underrepresentation of women leadership in academia. Therefore, the use of qualitative approach was the best selection to get answer to research questions posed in the study. It would also be helpful to know how male and female explain their experiences while showing any signs of bias and stereotyping. This narrative inquiry was aimed to explore the issue of stereotypical perceptions of people which might affect the women leaders in academic sector. Landrum and Garza (2015), settled that exploratory studies help researchers to give meanings to individuals' experiences regarding some particular phenomenon. Qualitative approach using narrative analysis methodology while collecting open ended interview questions using story telling aspect tend help to collect people bias and stereotypical perceptions regarding women leadership roles in academia.

\section{Sample of Study}

For this study twenty $(\mathrm{N}=20)$ respondents were selected from HEC recognized universities of Lahore, Pakistan. Among which, 10 respondents (five males and five females) were selected from Public Sector Universities and other 10 respondents (five males and five females) were chosen from Private Sector Universities of Lahore, Pakistan.

\section{RESEARCH FINDINGS}

Table 1: Sample size of Respondents 


\begin{tabular}{llcc}
\hline Sectors & Name of the University & Teacher Educators & No of teachers \\
\hline \multirow{4}{*}{ Private } & Female & 1 \\
& Private university 1 & Male & 1 \\
& Private university 2 & Female & 1 \\
& & Male & 1 \\
& Private university 3 & Female & 1 \\
& & Male & 1 \\
& Private university 5 & Female & 1 \\
& & Male & 1 \\
& Public University 1 & Female & 1 \\
& & Male & 1 \\
& Public University 2 & Female & 1 \\
& & Male & 1 \\
Public & Public University 3 & Female & 1 \\
& & Male & 1 \\
& Public University 4 & Female & 1 \\
& & Male & 1 \\
& Public University 5 & Female & 1 \\
& & Male & 1 \\
& & Female & 1 \\
\hline
\end{tabular}

\section{Qualitative Narrative Analysis}

The responses of participants were analyzed through "Coding Process". The words in stories that appear frequently were given certain codes so it becomes easy to handle large amount of responses and to understand data in a systematic way. This process was done with the help of NVivo software. The next step was the development of "Sub Themes" which are data driven. Finally, after the process of initial coding "Themes" emerged from the whole data. The process of initial coding was done by using NVivo in which three major themes were formed from the missing role of women leadership in the academia.

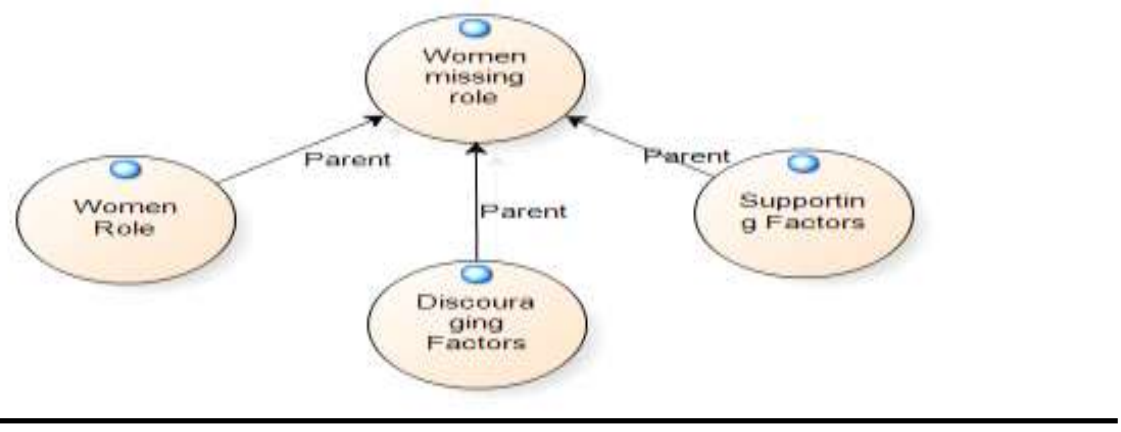


Figure 1: Hierarchy of Identified Themes Map of Thematic Analysis in NVivo for Missing Role of Women Leadership in the Academia.

Results shows that three themes emerged from the data that were "women role", "discouraging factors", and "supporting factors".

\section{Sub Themes}

By using NVivo software, the sub themes were generated in order to organize a group of data like repeated words, attributes, and ideas by emerging them into their corresponding themes. Each theme has some sub themes.

\section{Women professional Roles in Academia}

The first theme was "Women role".

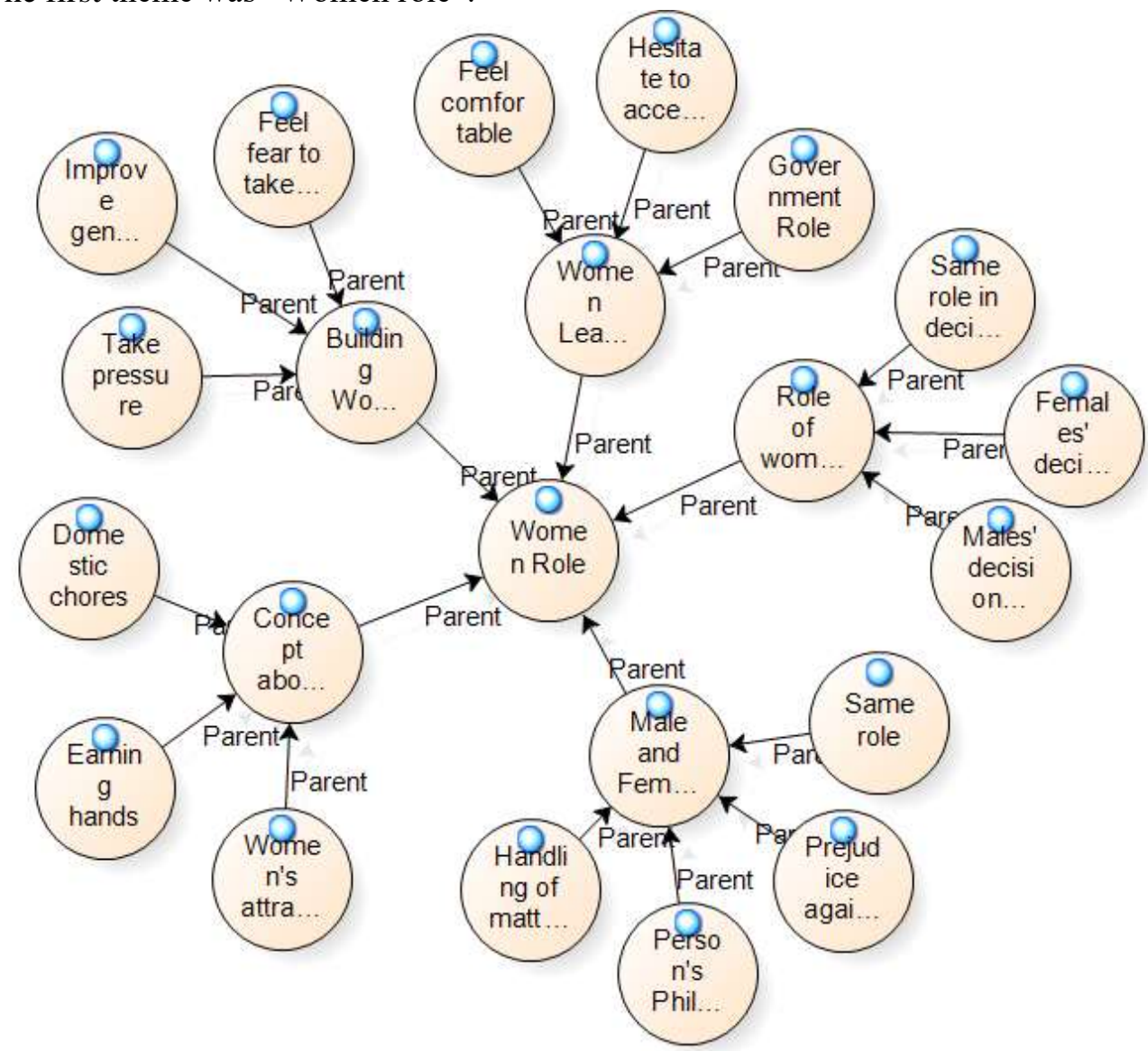

Figure 2: Hierarchy of Identified Sub Themes Map of Thematic Analysis in NVivo for Women Role. 
Figure 2 indicated that "Concept about Women Social Role", "Role of women in Decision Making", "Women Leadership in Different Disciplines", "Building Women Leadership in the Academia", and "Male and Female leadership styles in Academia" are the main sub themes that narrate the professional role of women at higher position of academia.

\section{Women's Aspirations for Social Role}

While asking twenty respondents about the women social role, they explained that women appearance matters a lot to impress people in the social situations. Females have to present their figure at attractive level to catch the attention of others to grab more opportunities. Although, some respondents described that women role is just to look after the family and take care the domestic chores. Pakistan is a chauvinistic society where men have more social roles as compared to women and they are more responsible for running family set up. They are the earning hands of their parents to make decisions regarding the welfare of their family members. One female respondent said:

"I am working as senior lecturer and managing all departmental affairs but when it comes to nominate someone for departmental affairs then my male colleague is always privileged to appoint for managerial tasks. I wish to lead in the administrative tasks for decision making but I am not encouraged" $(\mathrm{R}, 2)$.

However, on the other side, men believe on women capabilities as a leader and they assume female can perform professional roles diligently.

"I think we are in $21^{\text {st }}$ century where females are free and independent and they are working side by side male, they are respected and regarded in all fields of life. At my workplace, there are several females who are working at administrative level and managing their departmental responsibilities without any gender discrimination" (Male Respondent, 8).

\section{Women's Style of Decision Making}

While asking respondents about women role as decision maker, majority of the respondents stated that decision making is a male oriented function and females cannot become good decision makers due to their weak capacity of being treated neglected due to family background and domestic responsibilities. However, few respondents reasoned that women have equal social roles in the society and they are wise and educated. Therefore, we should provide them sufficient opportunities to lead the team work and participate into social meeting where they can raise their voice.

One male respondent narrated: 
"At my organization, where female is a managing director, she takes wrong decisions without seeking males' opinion and they suffer afterwards due to low supply in material. Our company is getting loss due to her decision making, she behaves in a harsh way so we feel uncomfortable to give her suggestions" $(\mathrm{R}, 7)$.

On the opposite side, some respondents are in favor of women leadership: another respondent described:

"In my perspective, men don't make decisions independently, there is always a woman behind them who taught them how to do when to do what to do, that's why it's a wrong concept that women are weak and treated as slaves like past. Only difference lies that we are not trusting their abilities and pushing them behind intentionally" $(\mathrm{R}, 12)$.

\section{Women Leadership in Different Departments}

Due to some education reforms government has introduced quota system in order to make sure that women have equal opportunities side by side men in different departments. Hence, majority of respondents agreed that government is taking some encouraging steps to ensure the participation of the women into different department where they are managing leading positions such as human resource department, finance and tax department, bureaucracy and education departments. Though, they believed that women themselves hesitate to come in front and give excuses to accept the responsibility of their leading role.

Another female respondent 7 gave her view that:

"I really enjoy my authoritative role and want to be prominent in terms of leading the teams. I know my ability to govern my department, I receive prejudice behavior of men regarding my policies and decisions. Though I am fair in my dealing but they assume that I support more young females and assign authoritative roles. Whenever I conduct my meeting with them, I show them the tasks divisions and equal proportion of their participation but their thinking patterns and behavior don't look comfortable".

To support women leadership roles male respondent said:

"Government should create business opportunities for women so that they can start up small scale business at their home by managing their domestic tasks. Government can pass on instructions to the education institutes to train these women who have potential to become good entrepreneurs in future. I think we need to launch this approach like in China women are doing small business and doing so well. At the end their effort and struggle help them to reach at the peak where they wish to reach at that designation." $(\mathrm{R}, 12)$.

\section{Building Women Leadership in the Academia}


Experts believe to improve gender equality at the workplace to give equal roles and leadership positions to women. There has been a debate on the subject of women in leadership roles and it boils down to the pride and the prejudice. Respondents were asked about the women's missing role in the academia and how do they carry their role being a leader. Some respondents explained that women are less likely to be passed over for promotions or receive unfair raises relative to their male counterparts. Some of them expressed their thoughts that women possess the potential and talent to perform and execute the same tasks managed by male employees but the sad part is the male chauvinistic society that doesn't acknowledge the efforts and support of women.

One male respondent said:

"I have worked under women leadership many times; I have worked with them in the corporate sector. Women do bring different perspectives to deal with the different nature of tasks. In this university, we have female as director who is managing both academic and finance departments who is dealing all matters by using her intellect" $(\mathrm{R}, 1)$.

However, at senior leadership positions, females should be vigilant and determined when they take their decision. I have observed my university, our head changes her mind when it comes to social pressure and authority orders, she reverts her decisions and modify the notifications.

While supporting women in terms of getting leadership roles, one of the female respondents said:

"I have observed that male control the male patriarchy and they chose those women for leadership who can control women empowerment and implement womencontrolled role in leadership. Women do have potential and unique power of being able to look at the world's issues and discover solutions that transform lives and make the world a better place. At my university, my principal is not supporting to encourage the young female faculty in terms of taking part in capacity development programs. She knows the talent of myself but she feels insecure of me. So women leadership is more challenging in terms of getting prominent roles under their supervision" $(\mathrm{R}, 11)$.

\section{Male and Female Leadership Styles in Academia}

Respondents of the study are in different opinion of male and female leadership styles however, they believe both can play effective roles in terms of planning, organizing and managing different tasks. Males are assumed to be wiser in terms of deciding the conflicting issues of the institutions as they run their families and have more knowledge about the financial matters and how to generate resources. Only the prejudice exit in our mind is to consider women as weak for the social roles and their empowerment. 
One female respondent explained:

"I like my female head of institute she is wise, competent and polite in terms of managing the university affairs, she is very smart to identify the potential of the faculty. She believes in democracy and invites everyone to take part in the discussion on academic affairs. She has made some amendments to ensure the female faculty participation in the academic and research board and nominated more female faculty in the purchase and auction committees where female faculty can make decision making" ( $\mathrm{R}, 9)$.

One male respondent expressed his thoughts regarding the leadership styles of the institution head:

"I believe a person's philosophy and ideology matters a lot in decision making. If a person is coming from the encouraging environment and have more supporting environment, he/she will encourage the faculty members to take part in all academic affairs. My previous head of institution was from foreign university. He supported all gender-based policies and he had an excellent leadership skill. He was a great supporter of women leading and governing roles in the institution. Though, some male members were unhappy due to their strategic leadership".

Few respondents were in favor of female leadership styles and supported their empowerment in the society. Another female respondent said:

"Women who take care of the future generations, if they get leadership chances they get to know how to train their children to become responsible citizens of the country. I believe women have more coaching style leading role who tend to believe in coaching the employees and make the assigned tasks easier according to their capacity. Women are successful leaders at the dean and director position in other universities" $(\mathrm{R}, 13)$.

\section{Discouraging Factors}

The second theme was "Discouraging Factors".

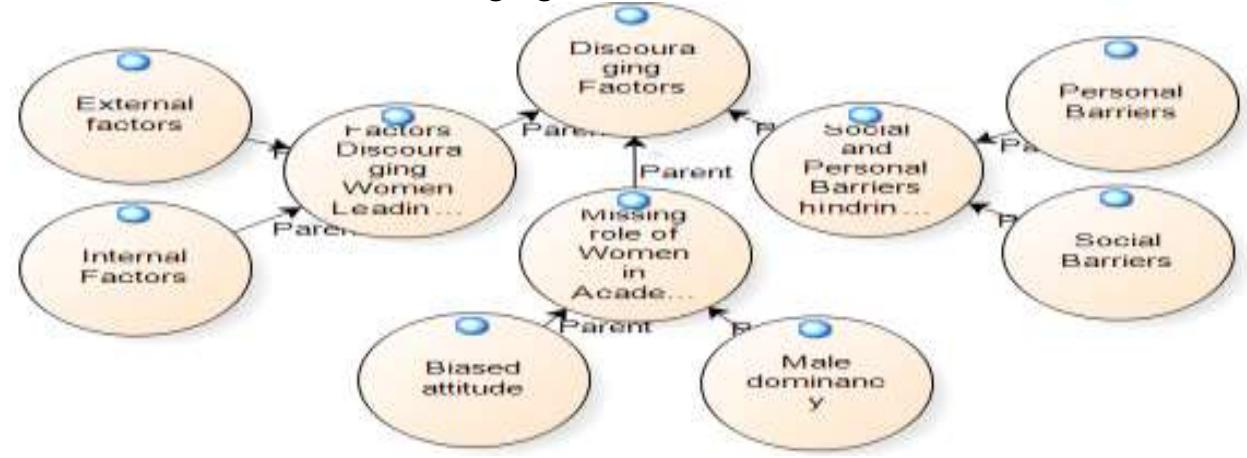

Figure 3: Hierarchy of Identified Sub Themes Map of Thematic Analysis in NVivo for Discouraging Factors. 
Figure 3 indicated that "Factors Discouraging Women Leading Role". It showed that "Social and Personal Barriers hindering women leadership in Academia" and "Missing role of Women in Academia" are the main discouraging factors that reduce the participation rate of women in leadership.

\section{Factors Discouraging Women Leading Role}

All the respondents revealed that there are some factors that create hurdle in the way of women leadership roles such as family restrictions, cultural issues, physical harassment, and travelling insecurity that don't allow women to take authority. Without having experience, they tend to be reluctant to come in front and accept the leading roles. Some respondents also expressed that women have the courage to take care of the administrative tasks but some external factors affect their performance. Another factor is the females' avoidance to develop strong networks that help to establish links with different organizations for the welfare of the institution.

Regarding the factors encounter in the way of women leadership, one male respondent said:

"Networking is described as process of exchanging information, or services in between individual or institutions that aims at creating a productive relationship for employment. I have observed that when it comes to interact with the foreign delegation to make a deal about professional development of the faculty, my female head asked me to conduct meeting with them and she refused to see them in person" $(\mathrm{R}, 13)$.

\section{Social and Personal Barriers Hindering Women Leadership in Academia}

According to most of the respondents, personal barriers such as early marriage, religious restrictions to avoid male interaction and establishing networking, long distance travelling, spending long hours at workplace, workplace harassment and bulling attitude from students are the main reasons in the way of women leadership in the academia.

One female respondent expressed her views and she said:

"I am enthusiastic to take part in professional development and workshop but I cannot go out of city as my family does not allow me to travel alone and stay there alone. So, I refuse to attend those workshops, my family said I am getting married soon so I should be careful for my safety and reputation if they see me with male colleagues, they will make gossips" $(\mathrm{R}, 12)$.

One male respondent said on the opposite way:

"I assume all men and women are equal in terms of work responsibilities, if women cannot perform equal work responsibilities then they should not join academic institutions, they go to home early and we are supposed to complete their work at late 
working hours we also have families and home. In my opinion, women should decide whether they want their social role or domestic role, then they should jump into any organization they occupy work position and mistreat it afterwards" $(\mathrm{R}, 16)$.

\section{Missing Role of Women in Academia}

According to the respondents that women are performing their social role very well at universities, they are performing their leadership styles and managing roles in terms of teaching and administrative tasks. However, they believed that they are not getting that support as institution provides to male administrators. If female faculty member is senior and she is neglected intentionally to come in front and to lead the event management and other tasks.

"I am talented and efficacious but my head of institution doesn't want to accept the women empowerment, he is so conservative and old-fashioned man. He encourages male faculty members to take leading role and when it comes to the casual tasks such as admission securing, he suggested our names. He is not supporting young talented female faculty members" $(\mathrm{R}, 8)$.

Rest of the respondents said, there are biased attitudes exist towards women leadership but there should be equal gender opportunities for professional and career oriented women. There are mentoring programs that we can offered them to develop their efficacy to accept the leadership and front roles. It depends on the institution ideology to favor more male members or female faculty members. It also varies from person to person how they take it for their understanding.

\section{Supporting Factors}

The third theme was "Supporting Factors".

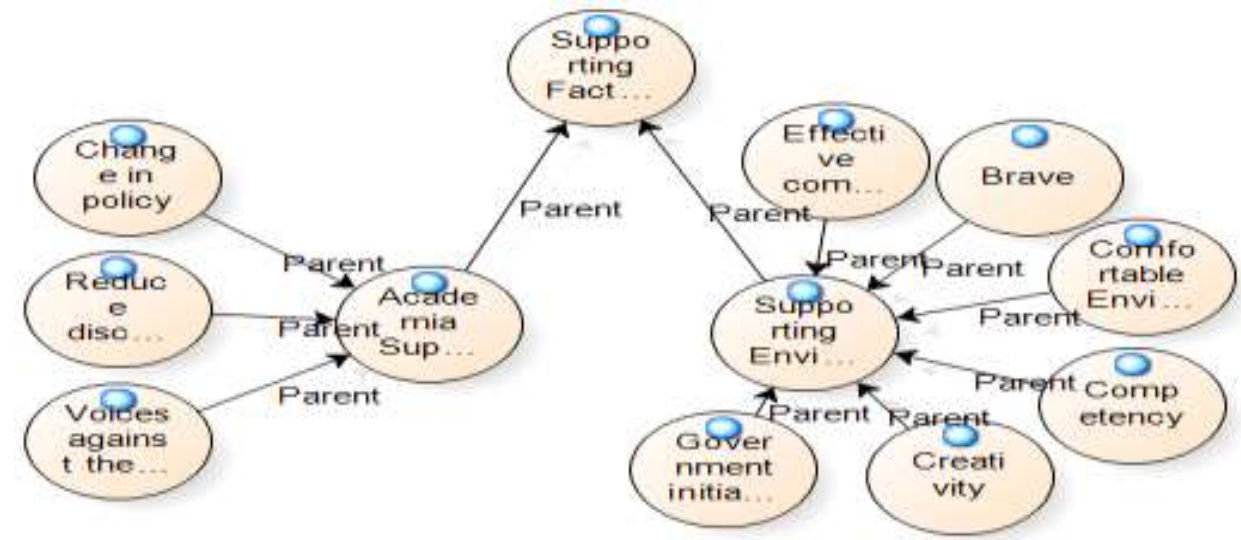

Figure 4: Hierarchy of Identified Sub Themes Map of Thematic Analysis in NVIVO for Discouraging Factors. 
Figure 4 shows that "Supporting Environment for women leadership", and "Academia Support in relation to women leadership" and "Missing role of Women in Academia" are the supporting factors that enhance the participation rate of women in leadership.

\section{Supporting Environment for Women Leadership}

The ability to communicate effectively is perhaps the most significant skill for a strong leader, we need innovative and inspiring leaders to bring about change in the development and growth of the organization. Women have such creativity and innovative gestures to bring diversity in their working styles, social skills to cater the responsibilities of the organization. Respondents of the study revealed their opinions and said that women are occupying vice chancellor's role in the academia and it is not true that they face gender biased they have equal chance of selection on higher positions based on competency. Respondents also highlighted that if they are given comfortable environment they can accept challenging roles being leader only the social setup creates a problem for them.

Male respondent said on the supporting environment in favor of women leadership: "By strengthening the leadership capacities of female, we need to open comfortable zones of support that will enable them to work in a smooth way and resolving conflicting issues easily. They are brave and courageous only social setup turned down their passion to resume their leading roles" $(\mathrm{R}, 19)$.

Female faculty member described her views as:

"I was selected as head of institution but I could not join the university because of long distant travelling, I am near closing line of my retirement. I cannot commute on daily basis to university as it is out of city. They had no residency for employees and I was not aware the locality surrounding so I just refused to accept that leadership and did not promote into next scale." $(\mathrm{R}, 16)$.

So there are many factors that are creating hurdles in the way of women to accept the leadership roles. Government takes initiatives to provide all feasible resources and facilities that can make easier for women to accept that leading role.

\section{Academia Support in Relation to Women Leadership}

Majority of the respondents believe that institution can set up a policy to ensure women participation of taking charge of leadership in any department so they can feel honored and they can be more confident to accept such leadership roles. If institution is not supporting female faculty and give more preference to male members to become a member of all academic affairs, research boards, academic councils then this action discourages the women to accept responsible tasks and decision making tasks. 
One female respondent said:

"I participated in the academic council very well, gave nice suggestions and introduced innovative ideas but the convener of academic council discourages my ideas and nominated someone else in my replacement. Women are discouraged when it comes to higher order decision making and they suggest worthwhile recommendations so they are pushed down" $(\mathrm{R}, 3)$.

Academia support and cooperation is the key to achieve the milestone for women at leading positions, self-governing tasks and self-imposed decision cannot make employee happy to work in smooth way.

One male respondent said,

"There is no check on academic institution by Higher Education Commission, we face male harassment and bulling. We cannot raise our voices against the wrong policies of the head of the institution. We have been suffering from doing the clerical tasks without payment on the weekends but they were helpless to change this mafia system. If male cannot bear this sort of leader how female can bear this style of leadership and they will not think of becoming a leader whenever they are offered". (R, 9).

\section{RESULTS AND DISCUSSIONS}

After identifying and highlighting the "Patterns" and "Sequence" in the interviews of teacher educators, the researcher found some themes and sub themes regarding the missing role of women leadership in academia. Themes emerged from the analysis of data including "Women Role", "Discouraging Factors" that restrain women to participate in academia as a leader and "Supporting Factors". The study explored three different themes regarding missing role of women leadership in academia. The study found a mix of findings encompassing women role in leadership, discouraging factor and supporting factors. The findings explored happened to be well aligned to the prevalent literature in the field.

The first theme generated was named as "Women Role" which had five sub themes including "Concept about Women Social Role", "Role of women in Decision Making", "Women Leadership in Different Departments", "Building Women Leadership in the Academia", and "Male and Female leadership styles in Academia".

Codes such as domestic chores, earning hands, and women's attraction were found as the factors behind the theme of "Concept about Women Social Role". This finding obtained from present study was similar to the results found in the studies such as (Eklund et al., 2017; Subramanian, 2018; Tang and Tang, 2001). The author described that in Asian context women are more effected by their family responsibilities as compared to their male counterparts. Therefore, they opt part time or quit their 
professions to fulfil their domestic responsibilities.

The factor "Building Women Leadership in the Academia" showed that the most significant factor is the development of safe and friendly atmosphere at the workplace. Similar perspective was revealed in the study of Bajdo and Dickson (2001), who found that the organizations having more human orientation, gender equitable policies, performance oriented, less authoritative happened to have more women in leadership positions. For the last subtheme "Male and Female leadership styles in Academia" showed the factors including handling of matter, similar role, person's philosophy and prejudice against women as prominent styles of women leadership in academia. The study conducted in university sector of Lahore Pakistan by Abida et al., (2010) confirmed the findings that were obtained in present research describing that there is not a significant variation in male and female leadership styles playing leadership roles.

The second main theme revealed was labelled as "Discouraging Factors" having three sub themes including "Factors Discouraging Women Leading Role", "Social and Personal Barriers hindering women leadership in Academia" and "Missing role of Women in Academia". These findings were found aligned to the study by Bulloug (2008), who found that societies having less representation of women have some common factors due to social factors and home responsibilities.

The study found that personal barriers, and social barriers hinder women leadership to aspire to leadership roles whereas biased attitude and male dominancy were the cause of missing role of women in academia. These findings were corroborated by the studies carried out by (Papamarcos \& Watson 2006; Hijase, 2013). They explored that cultural values help in increasing or decreasing economic wellbeing of a country.

The results of the study found that multi layered factors work for the advancement of women leadership that include international trade, technology, supportive environment, Development of human capacities and economic wellbeing. Therefore, women leadership is a variable that is not possible with one initiative. It requires different kinds of changes in the organizational structure, Govt policies and professional development mechanism. The results identified the presence of biases towards women leaders in society. Respondents reported these biases are prevalent in policies and political conspiracies in the work places. The findings of the present study are similar to those revealed by Lahti (2013). He found three types of influential factors for the advancement of women leadership. These included traditional gender roles, structure of organizations, women's own perceptions and the competence. 


\section{RECOMMENDATIONS}

1. This study revealed that in Pakistani context, women role in leadership positions would require training, government policies, mentoring programs to empower their roles as a leader.

2. Study has implications for stakeholders including government, organizational structures and social change agents to devise policies to strengthen women leadership positions.

3. Findings suggest that universities should initiate leadership development programs for women such as access to advanced degrees such as doctoral, continuous training programs, training and professional development opportunities.

\section{REFERENCES}

Abida, K., Farah, N., \& Azeem, M. (2010). Gender Differences in Leadership Style at the University Level. International Journal of the Book, 7(3).

Asian Women's Gender Role, Work-family Balance, and Mental Health (2016). Retrieved from https://fass.nus.edu.sg/cfpr/wp-content/uploads/sites/17/2020/09/Oct16E.pdf

Bajdo, L. M., \& Dickson, M. W. (2001). Perceptions of organizational culture and women's advancement in organizations: A cross-cultural examination. Sex Roles, 45(5/6), 399.

Bolden, R., Gosling, J., Marturano, A., \& Dennison, P. (2003). A review of leadership theory and competency frameworks. Centre for leadership studies, University of Exeter.

Braun, S., Peus, C., \& Frey, D. (2018). Connectionism in action: Exploring the links between leader prototypes, leader gender, and perceptions of authentic leadership. Organizational Behavior and Human Decision Processes, 149, 129-144.

Bullough, Amanda M., "Global Factors Affecting Women's Participation in Leadership" (2008). FIU Electronic Theses and Dissertations. 184. https://digitalcommons.fiu.edu/etd/184

Cook, A., \& Glass, C. (2014). Above the glass ceiling: When are women and racial/ethnic minorities promoted to CEO? Strategic Management Journal, 35(7), 1080-1089.

Cook, S., \& Dong, X. Y. (2011). Harsh choices: Chinese women's paid work and unpaid care responsibilities under economic reform. Development and Change, 42(4), 947-965.

Chin, J. L. (2011). Women and Leadership: Transforming Visions and Current Contexts. In Forum on Public Policy Online (Vol. 2011, No. 2). Oxford Round Table. 406 West Florida Avenue, Urbana, IL 61801.

Christman, D. E., \& McClellan, R. L. (2012). Discovering middle space: Distinctions of sex and gender in resilient leadership. The Journal of Higher Education, 83(5), 648-670.

DeFrank-Cole, L., Latimer, M., Reed, M., \& Wheatly, M. (2014). The Women's Leadership Initiative: One University's Attempt to Empower Females on Campus. Journal of Leadership, Accountability \& Ethics, 11(1).

Eklund, K. E., Barry, E. S., \& Grunberg, N. E. (2017). Gender and leadership. Gender differences in different contexts, 129-150.

Eagly, A. H., \& Carli, L. L. (2009). Navigating the Labyrinth. School Administrator, 66(8), 1016. 
Eagly, A. H., \& Chin, J. L. (2010). Diversity and leadership in a changing world. American Psychologist, 65(3), 216.

Eagly, A. H., \& Karau, S. J. (2002). Role congruity theory of prejudice toward female leaders. Psychological Review, 109(3), 573.

Eagly, A. H., Eagly, L. L. C. A. H., \& Carli, L. L. (2007). Through the labyrinth: The truth about how women become leaders. Harvard Business Press.

Ely, R. J., Ibarra, H., \& Kolb, D. M. (2011). Taking gender into account: Theory and design for women's leadership development programs. Academy of Management Learning \& Education, 10(3), 474-493.

Finstad-Milion, K., \& Naschberger, C. (2014). Is there a female career? unmasking perceptions of women's careers. Proceedings for the Northeast Region Decision Sciences Institute (NEDSI), 1129-1143. Retrieved from http://nedsi.org/

Haile, S., Emmanuel, T., \& Dzathor, A. (2016). BARRIERS AND CHALLEGES CONFRONTING WOMEN FOR LEADERSHIP AND MANAGEMENT POSITIONS: REVIEW AND ANALYSIS. International Journal of Business \& Public Administration, 13(1).

Haveman, H. A., \& Beresford, L. S. (2012). If you're so smart, why aren't you the boss? Explaining the persistent vertical gender gap in management. The ANNALS of the American Academy of Political and Social science, 639(1), 114-130.

Hechanova, R. M., \& Cementina-Olpoc, R. (2013). Transformational leadership, change management, and commitment to change: A comparison of academic and business organizations. The Asia-Pacific Education Researcher, 22(1), 11-19.

Hejase, H., Haddad, Z., Hamdar, B., Massoud, R. M., \& Farha, G. (2013). Female leadership: An exploratory research from Lebanon. American Journal of Scientific Research, 86, 28-52.

Hoare, J., \& Gell, F. (2009). Women's leadership and participation: Case studies on learning for action. Oxfam GB.

Johns, M. L. (2013). Breaking the glass ceiling: Structural, cultural, and organizational barriers preventing women from achieving senior and executive positions. Perspectives in Health Information Management/AHIMA, American Health Information Management Association, 10 (Winter).

Johnson, S. K., Murphy, S. E., Zewdie, S., \& Reichard, R. J. (2008). The strong, sensitive type: Effects of gender stereotypes and leadership prototypes on the evaluation of male and female leaders. Organizational Behavior and Human Decision Processes, 106(1), 3960.

Keskes, I. (2014). Relationship between leadership styles and dimensions of employee organizational commitment: A critical review and discussion of future directions. Intangible Capital 10(1): 26-51. Retrieved from on 14th April 2014 from http://dx.doi.org/10.3926/ic.476

Lahti, E. (2013). Women and leadership: factors that influence women's career success: female leaders' reflections on their career development and leadership. LAHTI UNIVERSITY OF APPLIED SCIENCES

Landrum, B., \& Garza, G. (2015). Mending fences: Defining the domains and approaches of quantitative and qualitative research. Qualitative Psychology, 2(2), 199209. https://doi.org/10.1037/qup0000030 
Laud, R. L., \& Johnson, M. (2013). Journey to the top: Are there really gender differences in the selection and utilization of career tactics? Journal of Organizational Culture, Communications and Conflict, 17(1), 51.

Lechman, E., \& Okonowicz, A. (2013). Are women important for economic development? Womens' participation in the labor market and their contribution to economic growth in 83 countries. Corporate Social Responsibility and Women's Entrepreneurship around the Mare Balticum, 310.

Lennon, T., Spotts, D., \& Mitchell, M. (2013). Benchmarking women's leadership in the United States. Colorado Women's College, University of Denver. www.womenscollege.du.edu/media/documents/BenchmarkingWomensLeadershipinth eUS.pdf

Maaitah, R., Oweis, A., Olimat, H., Altarawneh, I., \& Al Maaitah, H. (2012). Barriers hindering Jordanian women's advancement to higher political and leadership positions. Journal of International Women's Studies, 13(5), 101-122.

Madden, M. (2011). Gender Stereotypes of Leaders: Do They Influence Leadership in Higher Education? Wagadu: A Journal of Transnational Women's \& Gender Studies, 9.

Maloş, R. (2012). Leadership styles. Annals of Eftimie Murgu University Resita, Fascicle II, Economic Studies. 421-426.

McCleskey, J. (2014), "Emotional Intelligence and Leadership: A Review of the Progress, Controversy, and Criticism", International Journal of Organizational Analysis, Vol. 22 No.1, pp. 76-93.

Morley, L., \& Crossouard, B. (2015). Women in Higher Education Leadership in South Asia: Rejection, Refusal, Reluctance, Revisioning.

Papamarcos, S. D., \& Watson, G. W. (2006). Culture's consequences for economic development: An empirical examination of culture, freedom, and national market performance Journal of Global Business and Technology, 2(1), 48-58.

Parker, K., Horowitz, J. M., \& Rohal, M. (2015). Women and Leadership: Public Says Women are Equally Qualified, but Barriers Persist. Washington, DC: Pew Research Center, 1-56.

Rudman, L. A., Moss-Racusin, C. A., Phelan, J. E., \& Nauts, S. (2012). Status incongruity and backlash effects: Defending the gender hierarchy motivates prejudice against female leaders. Journal of Experimental Social Psychology, 48(1), 165-179.

Subramanian, K. R. (2018). Social and Cultural Expectations and Changing Role of Women. International Journal of Engineering and Management Research (IJEMR), 8(2), 110117.

Tang, T. N., \& Tang, C. S. (2001). Gender role internalization, multiple roles, and Chinese women's mental health. Psychology of Women Quarterly, 25(3), 181-196. 